\title{
Evaluation of the Clamping Force of Bolted Joints Using Local Mode Characteristics of a Bolt Head
}

\author{
Naoki Hosoya ${ }^{1}$ (D) $\cdot$ Takahiko Hosokawa $^{2}$ - Itsuro Kajiwara ${ }^{3}$. Shinji Hashimura ${ }^{1} \cdot$ Feblil Huda $^{4}$
}

Received: 11 September 2017 / Accepted: 28 September 2018 / Published online: 8 October 2018

(c) The Author(s) 2018

\begin{abstract}
It is important to determine and control the clamping force of a bolted joint. Due to its simple setup, the torque control method is typically used to control the clamping force when tightening bolts. After tightening, hammer tests, ultrasonic techniques and methods employing sheet materials as sensors are often used. Many methods have been proposed, but using them to determine and control the clamping force during or after tightening bolts is labor intensive or expensive. Here we conduct impact tests with an impulse hammer combined with experimental modal analysis to determine the clamping force by interpreting the change in the local mode frequency of a bolt head in the high frequency region as a function of the clamping force. To demonstrate the applicability of our method, we also investigate its limits with regard to bolt sizes.
\end{abstract}

Keywords Vibration $\cdot$ Non-destructive testing $\cdot$ Clamping force $\cdot$ Bolted joint $\cdot$ Experimental modal analysis

\section{Introduction}

Multiple bolts are often used to join or restrain the components of a structure. Because loosening of these bolts may damage the structure, it is important to be able to monitor and control the clamping force of bolted joints [1]. Methods

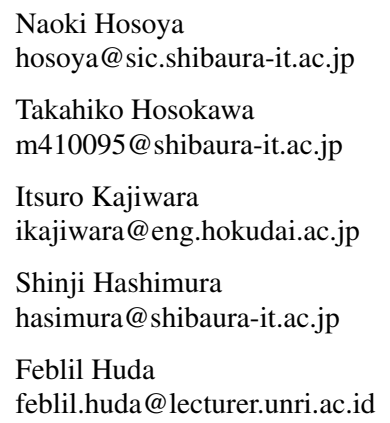

1 Department of Engineering Science and Mechanics, Shibaura Institute of Technology, 3-7-5 Toyosu, Koto-ku, Tokyo 135-8548, Japan

2 Division of Mechanical Engineering, Shibaura Institute of Technology, 3-7-5 Toyosu, Koto-ku, Tokyo 135-8548, Japan

3 Division of Human Mechanical Systems and Design, Hokkaido University, N13, W8, Kita-ku, Sapporo 060-8628, Japan

4 Department of Mechanical Engineering, University of Riau, Kampus Bina Widya, Jl. HR Subrantas km 12,

5, Pekanbaru 28293, Riau, Indonesia to control the clamping force while tightening bolts include the torque control method, the turn-of-nut method, and the torque gradient control method. Due to its simplicity, the torque control method is the most widely used [2]. After bolt tightening, hammer tests are traditionally used to determine the clamping force. In addition, commercially available methods using ultrasonic waves exist. [3-6]. However, these methods have some limitations in practical use. The disadvantage of hammer test is due to the skill, experience and target frequency (audible frequency) of the experimenter. A measurement accuracy of the clamping force obtained by the ultrasonic method depends on the dimension precision of a bolt such as a parallelism and smoothness of both edge faces of a bolt, and bent bolt. To improve the measurement accuracy in the ultrasonic method, additional processes have to be executed against all bolts of the bolted joints, because, in general, store-bought bolts with low precision are used for usual bolted joints. Therefore, a dozen methods in reference to the clamping force of bolted joints have been studied; for instance, an improved tightening method [7, 8], an effect on lubrication [9], a health monitoring [10, 11], damping mechanism [12], and loosening subjected to vibration [13-25].

We are currently developing a method to detect bolt loosening based on the Recognition-Taguchi method and a non-contact vibration test that uses laser ablation as the excitation force [26]. This method takes advantage of the fact that any damage to a structure greatly affects the natural fre- 
quency and vibrational mode shapes in the high frequency region of several tens of $\mathrm{kHz}$ [26]. Methods that use sheet sensors are also being considered, in which the changes in the natural frequency of the sheet sensors are interpreted as changes in the clamping force of the bolted joint [27]. Consequently, many methods have been proposed to measure and control the clamping force of a bolted joint during or after tightening, but none have reasonable labor and financial costs. If the clamping force of a bolted joint can be determined without using special equipment or adding to the structure of the bolted joint, similar to the sheet sensor method, it would contribute to the development of a more practical method to control the clamping force.

In this study, the clamping force of a bolted joint is determined via impact testing with an impulse hammer and experimental modal analysis. Changes in the local mode frequency of the bolt head in the high frequency region are correlated with changes in the clamping force. If changes in the clamping force can be determined from the changes in the natural frequency (mode) of the bolted joint, it would be difficult to determine which mode to monitor because natural modes can vary infinitely with the size and shape of the bolted joint. However, if the changes in the local mode frequency can be interpreted as changes in the clamping force, then the measurement process would be simplified.

The bolt head of the bolted joint focused in our experiment can be considered like a cantilever with elastic suspensions composed of translational and rotational springs. The local mode of the bolt head can be assumed to vibrate such as the vibrational mode shape of this cantilever. The local mode frequency decreases as the clamping force decreases, because the joint stiffness (translational and rotational springs) can be assumed to be relatively descended as the clamping force decreases. In the previous paper, Okugawa et al. [28] had investigated analytically the relationship between natural frequencies of a smart washer and a clamping force. They assumed the smart washer as a cantilever with elastic suspensions. In the paper, the natural frequencies when the clamping force is sufficiently large are the same as ones with fully fixed condition. Hence, an experimenter only has to measure the natural frequencies of the smart washer to detect a clamping condition of the bolted joint, because the natural frequencies decrease as the clamping force decreases.

We take advantage of this perception [28]. By the same token, the joint stiffness of the bolted joint decreases as the clamping force decreases. Therefore, the local mode frequency of the bolt head decreases as the clamping force decreases. More specifically, we should monitor the change in the local mode frequency. In case of monitoring the global mode frequencies, we need to know the vibrational mode frequency which has a susceptibility to the clamping force degradation from enormous modes of a target structure with bolted joints; however this common approach is unrealistic because this is a time-consuming method. Our technique has an advantage, which is hassle-free, because the technique just monitors the change in the local mode frequency of the bolted joint.

Here we determine the clamping force of a bolted joint by conducting mode characteristic analysis on the frequency response function (FRF) of a bolted joint, which is obtained from impact testing, as well as studying how the local mode frequency changes as a function of the clamping force. We also verify our method by examining the range of applicable bolt sizes.

\section{Clamping Force Evaluation Using Changes in the Local Mode Frequency of a Bolt Head}

\subsection{Bolted Joint}

To eliminate the effects of friction between fastened objects and the natural frequency of the bolted joint on the local mode frequency, we used a simple-shaped integral structure without natural modes in the measurement frequency range. A single bolt was fastened to the structure, and the relationship between the clamping force of the bolted joint and the local mode frequency was investigated. Figure 1 shows the $35 \mathrm{~mm}$ aluminum cube used in our experiments. Analysis of the cube's natural frequency using the finite element method (FEM) implemented in NASTRAN (HEXA solid elements, $1 \mathrm{~mm}$ mesh size) showed that the first natural frequency is $62 \mathrm{kHz}$. Therefore, the cube does not have any natural frequencies in the measurement range of up to $40 \mathrm{kHz}$. The bolt sizes used in the experiment and their corresponding recommended tightening torques are as follows: M4 $(0.75 \mathrm{Nm})$, M5 (1.4 Nm), M6 (2.6 Nm), and M8 (6.2 Nm). In this paper, we substituted the clamping force with the tightening torque value obtained from the torque control method. Additionally, we defined the clamping force ratio as the ratio of the desired tightening torque (desired clamping force) to the recommended tightening torque (recommended clamping force). The clamping force ratio varied between 0.1 and 1.0 in 0.1 increments. The bolts were tightened with torque wrenches (Tohnichi Mfg. Co., Ltd. SF40CN, SF6N, and SF12N).

\subsection{FRF Measurements}

The FRF of the bolted joint was measured by impact testing (Fig. 1). The bolted joint was freely supported by strings. In Fig. 1 (right), Points $1-5$ are the excitation points on the bolt head, while Points 6-9 are the excitation points on the cube. The response was measured by an accelerometer (PCB Inc. 352A25, mass: $0.7 \mathrm{~g}$, sensitivity: $0.263 \mathrm{mV} /\left(\mathrm{m} / \mathrm{s}^{2}\right)$, natural frequency: $>80 \mathrm{kHz}$ ) attached by an adhesive to the backside of Point 1 . Points $1-9$ were sequentially excited by a 


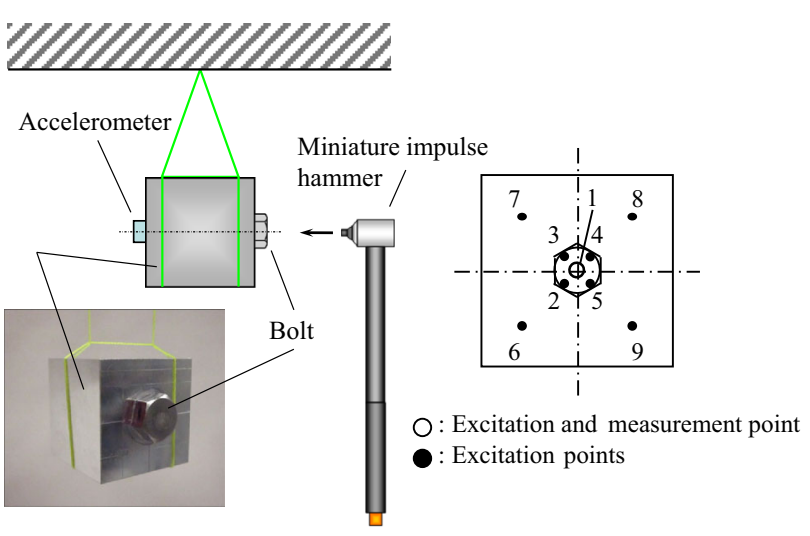

Fig. 1 Experimental setup (Color figure online) miniature impulse hammer (Brüel \& Kjær Sound \& Vibration Measurement A/S Type 8204, sensitivity: $22.26 \mathrm{mV} / \mathrm{N}$ ), and a total of 9 FRFs were measured by a spectral analyzer (A/D: National Instruments Co. NI PXI-4472B; software: Catec Inc. CAT-System). The FRFs were obtained by averaging 10 measurements, and rectangular window functions were employed.

\subsection{Local Mode of the Bolt Head}

Figure $2 \mathrm{a}-\mathrm{d}$ show the absolute value amplitudes, phase characteristics, and coherence functions of the auto-FRFs obtained at Point 1 for the different bolt sizes and clamping force ratios used. We initially investigated how the dynamic
Fig. 2 Measured FRFs of the 35-mm aluminum cube with one bolt. a M4, b M5, c M6, and d M8 (Color figure online)

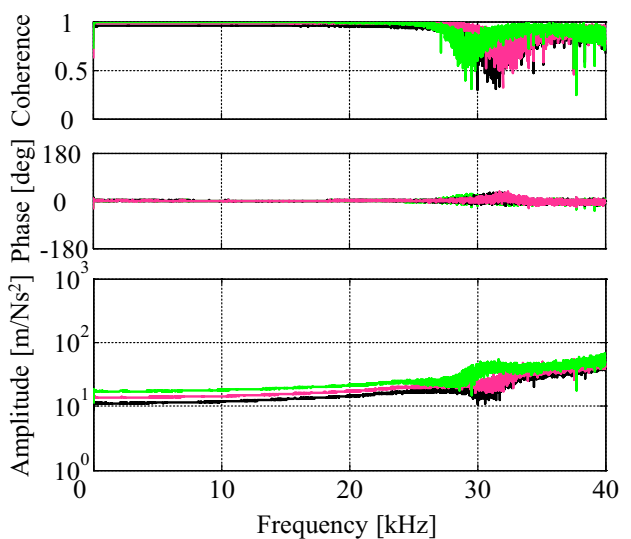

— : Clamping force ratio 0.1

— : Clamping force ratio 0.5

_ : Recommended (clamping force ratio 1.0)

(a)
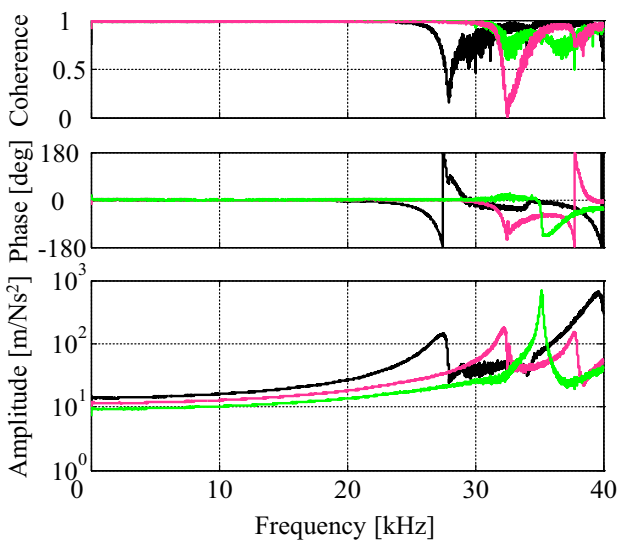

: Clamping force ratio 0.1

— : Clamping force ratio 0.5

_ Recommended (clamping force ratio 1.0)

(c)

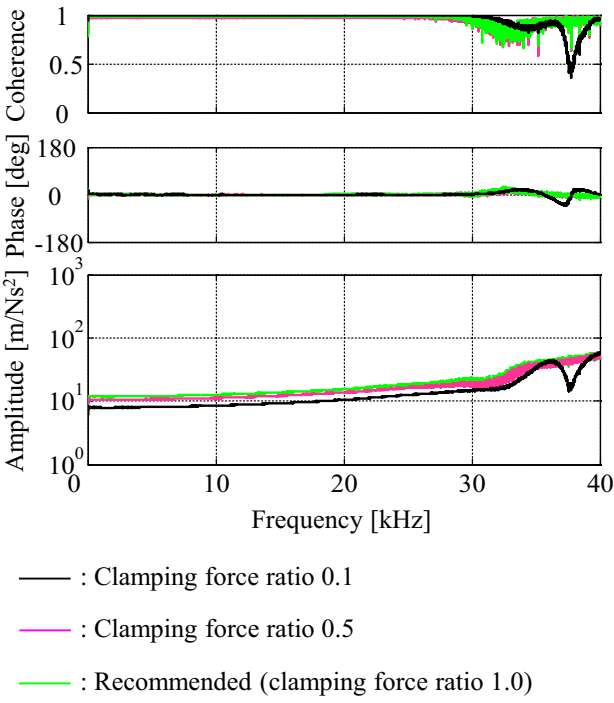

(b)
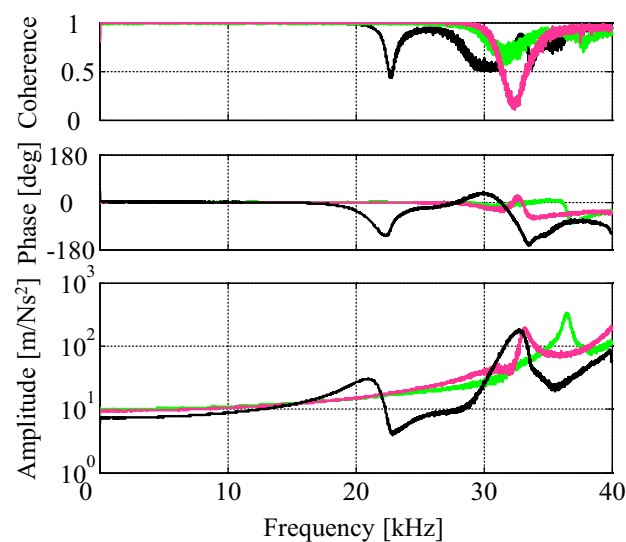

_ : Clamping force ratio 0.1

— : Clamping force ratio 0.5

_ : Recommended (clamping force ratio 1.0)

(d) 
(a)

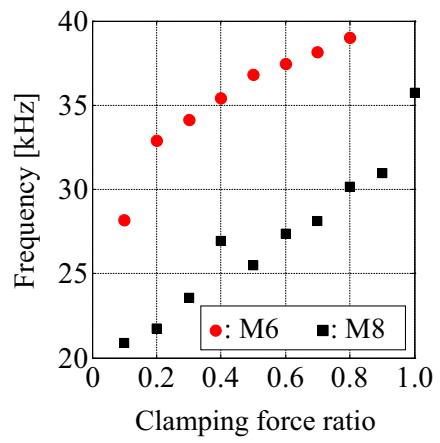

(b)

Fig. 3 Clamping force evaluation of the $35-\mathrm{mm}$ aluminum cube with one bolt. a Example of the local mode of the bolt head (bolt size: M6, natural frequency: $36.8 \mathrm{kHz}$, clamping force ratio: 0.5 ) and $\mathbf{b}$ the relationship between the local mode frequency of the bolt head and the clamping force ratio (Color figure online)

characteristics of bolted joints change as functions of the clamping force. Figure $2 \mathrm{a}$ and $\mathrm{b}$ indicate that the absolute value and the phase characteristics of the FRF hardly change with the clamping force of the bolted joint within the measurement frequency range of up to $40 \mathrm{kHz}$. However, the absolute values and the phase characteristics in Fig. $2 \mathrm{c}$ and $\mathrm{d}$ show that the natural frequencies shift to the lower frequency region as the bolt size (or bolt mass) increases. Thus, we conclude that our method can be used to determine the clamping force of bolted joints with bolt sizes of M6 or larger. If a non-contact excitation technique based on laser ablation [26, 29-36] or laser-induced plasma shock wave [37-47] can be used to excite target bolted joints for high frequency region over $40 \mathrm{kHz}$, a clamping force detection for miniature bolted joints may be realized.

Next, we conduct experimental modal analysis to determine whether the natural frequencies that show changes in Fig. $2 \mathrm{c}$ and $\mathrm{d}$ are local modes. Figure $3 \mathrm{a}$ shows an example of a local mode of a bolt head with an M6 bolt corresponding to a clamping force ratio of 0.5 . The natural frequency in Fig. 2c is a local mode. Similarly, local modes also exist for M8 bolts. Figure $3 b$ shows the relationship between the clamping force ratio and the local mode frequency for M6 and M8. As the clamping force increases, the local mode

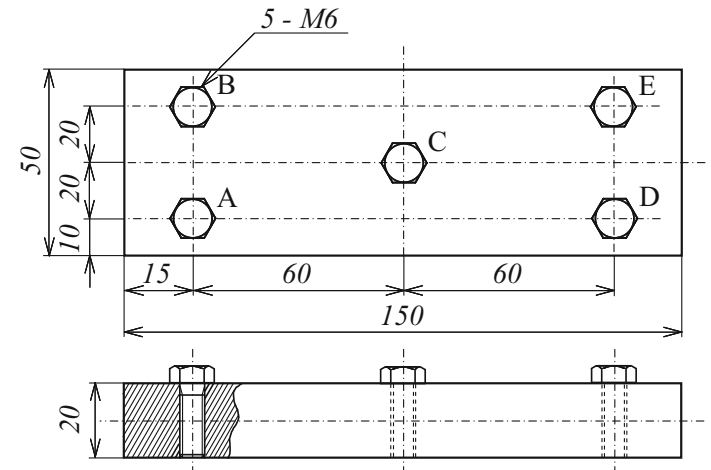

Material: Aluminum, Mass: $394.9 \mathrm{~g}$ (without bolts) (Unit: mm)

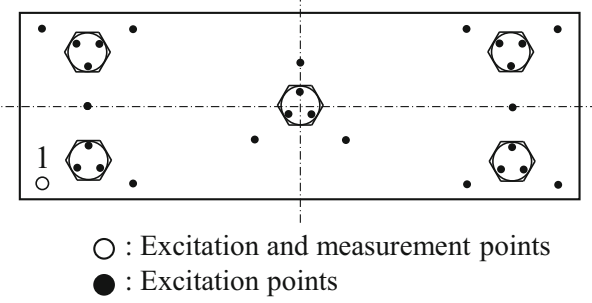

Fig. 4 Test piece

frequency shifts to a higher value, indicating that there is a relationship between the clamping force and local mode frequency. Although different bolt sizes result in different local mode frequencies, the general trend remains the same for M6 and M8 bolts. Therefore, this method determines a clamping force of bolted joints by observing changes in the local mode frequency of a bolt head in the high frequency region as functions of the clamping force.

\section{Case Study with Five-Bolt Structure}

To investigate the relationship between the clamping force and the local mode frequency for bolted joints with multiple bolts, we used a bolted joint consisting of a cuboid aluminum block $(150 \mathrm{~mm} \times 50 \mathrm{~mm} \times 20 \mathrm{~mm}, 398 \mathrm{~g})$ and five M6 bolts fastened at Points A-E as the test piece (Fig. 4). The following four cases were considered: the clamping force ratio for all bolts is 1.0 (case 0 ), the clamping force ratio for bolt $\mathrm{A}$ is 0.1 (case 1), the clamping force ratio for bolt $\mathrm{A}$ is 0.5 (case 2), and the clamping force ratio for bolt $\mathrm{C}$ is 0.1 (case 3 ). The bolts were tightened with a torque wrench. The lower panel in Fig. 4 shows the excitation and measurement points used in the experiment. The responses were measured by an accelerometer attached by an adhesive to the backside of Point 1.28 points were sequentially excited by a miniature impulse hammer to obtain measurements for the 28 FRFs with a spectral analyzer. The accelerometer, minia- 
Fig. 5 Clamping force evaluation of the part tightened by five bolts (case 1). a Measured FRF and vibrational mode shape for case 1 (clamping force ratio of bolt A: 0.1, natural frequency: $26.2 \mathrm{kHz}$ ), and $\mathbf{b}$ magnified measured FRF for case 1 corresponding to (a) (Color figure online)

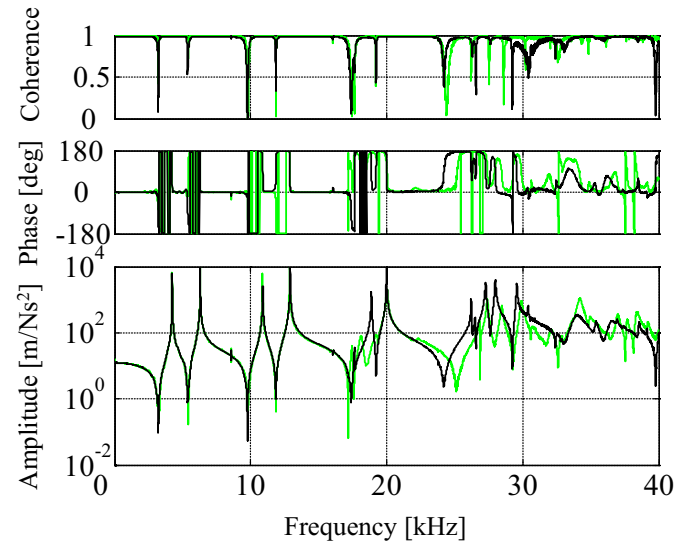

: Clamping force ratio for bolt A: 0.1 (case 1) Clamping force ratio for all bolts: 1.0 (case 0)

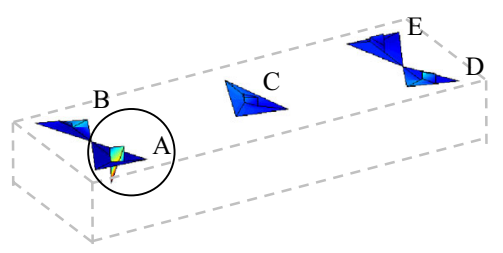

(a)

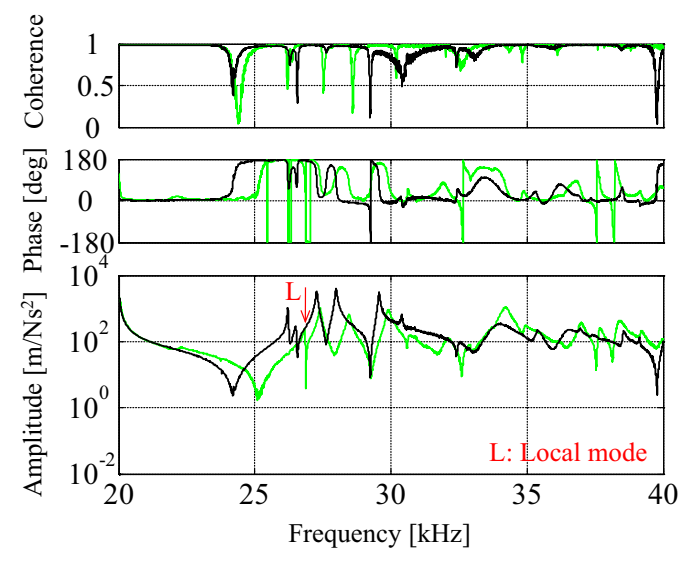

Clamping force ratio for bolt A: 0.1 (case 1)

: Clamping force ratio for all bolts: 1.0 (case 0 )

(b)

Fig. 6 Clamping force evaluation of the part tightened by five bolts (case 2). Measured FRF and vibrational mode shape for case 2 (clamping force ratio of bolt A: 0.5 , natural frequency: $33.7 \mathrm{kHz}$ ) (Color figure online)

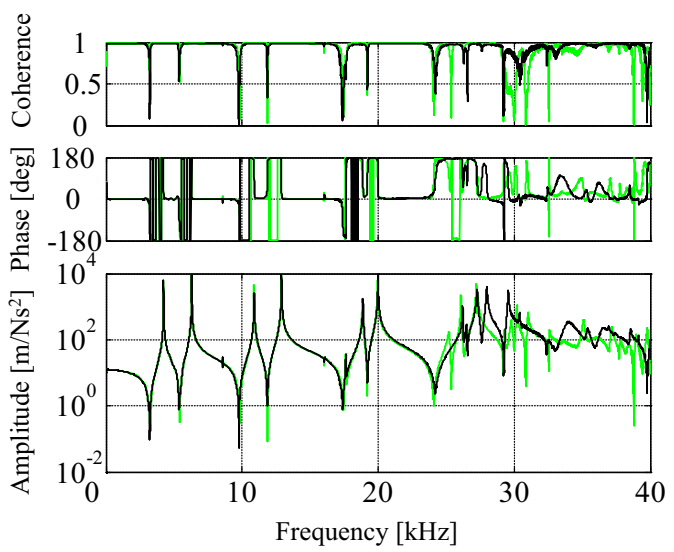

: Clamping force ratio for bolt A: 0.5 (case 2)

: Clamping force ratio for all bolts: 1.0 (case 0 )

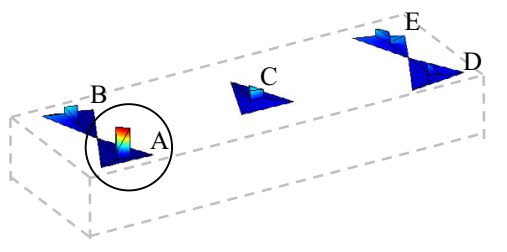


Fig. 7 Clamping force evaluation of the part tightened by five bolts (case 3 ). Measured FRF and vibrational mode shape for case 3 (clamping force ratio of bolt C: 0.1 , natural frequency: $18.7 \mathrm{kHz}$ ) (Color figure online)

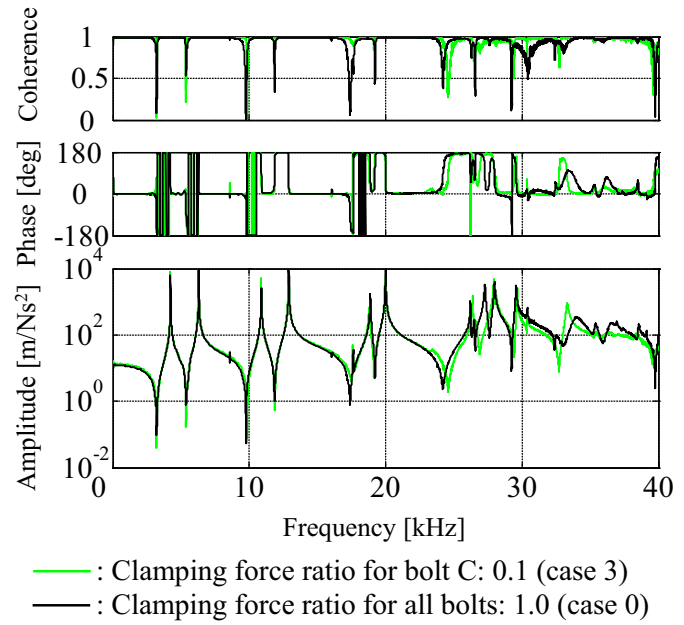

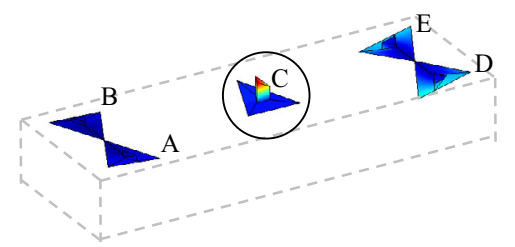

ture impulse hammer, spectral analyzer, and measurement conditions were the same as those described in the Sect. 2.3.

The relationship between the changes in the clamping force and the changes in the dynamic characteristics of the bolted joint was studied by comparing the auto-FRFs measured at Point 1 for cases $1-3$ with those for case 0 . Figures 5, 6 and 7 show the measured auto-FRFs for cases 1,2, and 3, respectively, where case 0 is overlaid for comparison. The corresponding vibrational mode shapes are shown on the right side of the figures. Figure $5 b$ shows an expanded view of the FRF in the frequency range of $20-40 \mathrm{kHz}$ for case 1. The data show that the shapes of the FRFs for cases 1-3 differ from that of case 0 in the high frequency region above $15 \mathrm{kHz}$. Additionally, a new peak (marked "L") is observed for case 1 but not case 0 . Comparing Figs. 5 and 7 indicates that even if the clamping force ratio is the same, the different positions of the loose bolt result in different changes in the dynamic characteristics in the high frequency region above $15 \mathrm{kHz}$ and different FRF shapes.

Next, we studied how the local mode frequency changes with the clamping force for cases 1-3. The local modes were obtained through experimental modal analysis of the high frequency region above $15 \mathrm{kHz}$ where the changes in the dynamic characteristics were observed in the FRFs in Figs. 5, 6 and 7. Comparing the right sides in Figs. 5 and 6 shows that when the clamping force of the bolted joint is changed by the same bolt, the local mode frequency shifts to a higher value (from 26.2 to $33.7 \mathrm{kHz}$ ) as the clamping force increases. This is the same trend observed in the Sect. 2.3. In the right sides of Figs. 5 and 7, the local modes appear for bolts A and C. This differs from case 0 .

These results demonstrate that the clamping force can be determined by understanding how the local mode frequencies change with the clamping force of the bolted joint. However, a more detailed analysis is required as this was only a case study, and the relationship between the clamping force and local mode frequencies may depend on factors such as the size of the bolted joint, the position of the bolts, and bolt size. Furthermore, if the relationship between the clamping force and local modes can be systematized through detailed experimental analyses of the local mode characteristics under various conditions, techniques may be developed to monitor the clamping force and evaluate bolt loosening after tightening.

\section{Conclusions}

We determined the clamping force of bolted joints through impact testing and experimental modal analysis, where the changes in the local mode frequency of the bolt heads in the high frequency region were interpreted as changes in the clamping force. To eliminate the effects of friction between fastened objects, our experiments employed integral structures with simple shapes. We monitored the auto-FRFs to investigate the changes of the dynamic characteristics of a bolted joint as functions of clamping force. The natural frequencies that undergo changes in the auto-FRFs are local modes, and the clamping force and local mode frequency are related. Our method can determine the clamping force of bolted joints for bolt sizes of M6 or larger.

As a case study, we examined the relationship between the clamping force and the local mode frequency for a bolted joint with multiple bolts. The relationship between the clamping force and local mode frequency persists for more complex bolted joints.

To realize full-field evaluation technique of the clamping force, we should systematize the relationship between the local mode frequencies and the clamping forces. At the same time, for realizing the inspection of the clamping force, it is required to determine the threshold of the clamping force degradation using the local mode frequency degradation. The 
local mode frequency and its amplitude of Fourier spectrum may vary by effect on lubrication, friction, fastening condition, an individual difference of a bolt, etc. It is expected that the threshold amplitude related to the local mode frequency can be determined through these investigations as our future works. Furthermore, other local modes with different frequencies sensitive to the clamping force may exist; this is also our future works.

Acknowledgements We thank the Japan Society for the Promotion of Science for their support under the Grants-in-Aid for Scientific Research programs (Grants-in-Aid for Scientific Research (B), Grant Nos. JP16H04291 and JP16H04286, and Grant-in-Aid for Challenging Exploratory Research, Grant No. JP17K18858).

\section{Compliance with Ethical Standards}

Conflict of interest The authors certify that there is no conflict of interest with the Japan Society for the Promotion of Science.

Open Access This article is distributed under the terms of the Creative Commons Attribution 4.0 International License (http://creativecomm ons.org/licenses/by/4.0/), which permits unrestricted use, distribution, and reproduction in any medium, provided you give appropriate credit to the original author(s) and the source, provide a link to the Creative Commons license, and indicate if changes were made.

\section{References}

1. National Aeronautics and Space Administration: Space shuttle: criteria for preloaded bolts. NSTS 080307 Revision A, Texas (1998)

2. Mori, K., Murakami, Y., Hashimura, S., Imai, R., Matsui, S.: A new measurement method of bolt tightening forces based on simultaneous loading of torque and compressive force. T. JSME 64(1998), 2212-2217 (1998). https://doi.org/10.1299/kikaic.64.2212

3. Koshti, A.: Ultrasonic measurement of the bending of a bolt in a shear joint. Exp. Mech. 38, 270-277 (1998). https://doi.org/10.10 07/BF02410389

4. Yasui, H., Tanaka, H., Fujii, I., Kawashima, K.: Ultrasonic measurement of axial stress in short bolts with consideration of nonlinear deformation. JSME Int. J. 42, 111-118 (1999)

5. Hirao, M., Ogi, H., Yasui, H.: Contactless measurement of bolt axial stress using a shear-wave electromagnetic acoustic transducer. NDT\&E Int. 34, 179-183 (2001). https://doi.org/10.1016/S09638695(00)00055-4

6. Jhang, K.Y., Quan, H.H., Ha, J., Kim, N.Y.: Estimation of clamping force in high-tension bolts through ultrasonic velocity measurement. Ultrasonics 44, e1339-e1342 (2006). https://doi.org/10.101 6/j.ultras.2006.05.190

7. Zhang, X., Wang, X., Luo, Y.: An improved torque method for preload control in precision assembly of miniature bolt joints. J. Mech. Eng. 58, 578-586 (2012). https://doi.org/10.5545/sv-jme.2 012.538

8. Hashimura, S., Komatsu, K., Inoue, C., Nakao, T.: A new tightening method of bolt/nut assembly to control the clamping force. J. Adv. Mech. Design Syst. Manuf. 2, 896-902 (2008). https://doi.org/10. 1299/jamdsm.2.896

9. Zou, Q., Sun, T.S., Nassar, S.A., Barber, G.C., Gumul, A.K.: Effect of lubrication on friction and torque-tension relationship in threaded fasteners. Tribol. T 50, 127-136 (2007). https://doi.or g/10.1115/IJTC2006-12090

10. Ritdumrongkul, S., Abe, M., Fujino, Y., Miyashita, T.: Quantitative health monitoring of bolted joints using a piezoceramic actuator-sensor. Smart Mater. Struct. 13, 20-29 (2004). https://doi.or g/10.1088/0964-1726/13/1/003

11. Argatov, I., Sevostianov, I.: Health monitoring of bolted joints via electrical conductivity measurements. Int. J. Eng. Sci. 48, 874-887 (2010). https://doi.org/10.1016/j.ijengsci.2010.05.009

12. Nanda, B.K.: Study of the effect of bolt diameter and washer on damping in layered and jointed structures. J. Sound Vib. 290, 1290-1314 (2006). https://doi.org/10.1016/j.jsv.2005.05.027

13. Chapman, I., Newnham, J., Wallace, P.: The tightening of bolts to yield and their performance under load. J. Vib. Acoust. Stress 108, 213-221 (1986). https://doi.org/10.1115/1.3269326

14. Zadoks, R.I., Yu, X.: An investigation of the self-loosening behavior of bolts under transverse vibration. J. Sound Vib. 208, 189-209 (1997). https://doi.org/10.1006/jsvi.1997.1173

15. Pai, N.G., Hess, D.P.: Three-dimensional finite element analysis of threaded fastener loosening due to dynamic shear load. Eng. Fail. Anal. 9, 383-402 (2002). https://doi.org/10.1016/S1350-6307(01) 00024-3

16. Pai, N.G., Hess, D.P.: Experimental study of loosening of threaded fasteners due to dynamic shear loads. J. Sound Vib. 253, 585-602 (2002). https://doi.org/10.1006/jsvi.2001.4006

17. Aragón, A., Alegre, J.M., Gutiérrez-Solana, F.: Effect of clamping force on the fatigue behaviour of punched plates subjected to axial loading. Eng. Fail. Anal. 13, 271-281 (2006). https://doi.org/10.1 016/j.engfailanal.2005.01.010

18. Nassar, S.A., Matin, P.H.: Clamp load loss due to fastener elongation beyond its elastic limit. J. Press Vessel Technol 128, 379-387 (2006). https://doi.org/10.1115/1.2217971

19. Hashimura, S., Socie, D.F.: A study of loosening and fatigue failure of bolted joints under transverse vibration. T JSME 72, 1297-1304 (2006). https://doi.org/10.1299/kikaic.72.1297

20. Zhang, M., Jiang, Y., Lee, C.H.: An experimental investigation of the effects of clamped length and loading direction on selfloosening of bolted joints. J. Press Vessel Technol 128, 388-393 (2006). https://doi.org/10.1115/1.2217972

21. Chakherlou, T.N., Oskouei, R.H., Vogwell, J.: Experimental and numerical investigation of the effect of clamping force on the fatigue behaviour of bolted plates. Eng. Fail. Anal. 15, 563-574 (2008). https://doi.org/10.1016/j.engfailanal.2007.04.009

22. Chakherlou, T.N., Abazadeh, B., Vogwell, J.: The effect of bolt clamping force on the fracture strength and the stress intensity factor of a plate containing a fastener hole with edge cracks. Eng. Fail. Anal. 16, 242-253 (2009). https://doi.org/10.1016/j.engfaila nal.2008.03.002

23. Oskouei, R.H., Chakherlou, T.N.: Reduction in clamping force due to applied longitudinal load to aerospace structural bolted plates. Aerosp. Sci. Technol. 13, 325-330 (2009). https://doi.org/10.101 6/j.ast.2009.06.001

24. Dinger, G., Friedrich, C.: Avoiding self-loosening failure of bolted joints with numerical assessment of local contact state. Eng. Fail. Anal. 18, 2188-2200 (2011). https://doi.org/10.1016/j.engfailana 1.2011.07.012

25. Yokoyama, T., Olsson, M., Izumi, S., Sakai, S.: Investigation into the self-loosening behavior of bolted joint subjected to rotational loading. Eng. Fail. Anal. 23, 35-43 (2012). https://doi.org/10.101 6/j.engfailanal.2012.01.010

26. Huda, F., Kajiwara, I., Hosoya, N., Kawamura, S.: Bolt loosening analysis and diagnosis by non-contact laser excitation vibration tests. Mech. Syst. Signal Process. 40, 589-604 (2013). https://doi. org/10.1016/j.ymssp.2013.05.023 
27. Tanaka, T., Okugawa, M.: Adopting supervisor for bolt loosening detection by using smart washer. T JSME 74, 2669-2676 (2008). https://doi.org/10.1299/kikaic.74.2669

28. Okugawa, M., Egawa, K.: Study on smart washer using piezoelectric material for bolt loosening detection. J. Jpn. Soc. Non-destr. Insp. 52, 511-516 (2003)

29. Kajiwara, I., Hosoya, N.: Vibration testing based on impulse response excited by laser ablation. J. Sound Vib. 330, 5045-5057 (2011). https://doi.org/10.1016/j.jsv.2010.09.036

30. Hosoya, N., Kajiwara, I., Hosokawa, T.: Vibration testing based on impulse response excited by pulsed-laser ablation: measurement of frequency response function with detection-free input. J. Sound Vib. 331, 1355-1365 (2012). https://doi.org/10.1016/j.jsv.2011.1 0.034

31. Hosoya, N., Kajiwara, I., Inoue, T., Umenai, K.: Non-contact acoustic tests based on nanosecond laser ablation: generation of a pulse sound source with a small amplitude. J. Sound Vib. 333, 4254-4264 (2014). https://doi.org/10.1016/j.jsv.2014.04.050

32. Hosoya, N., Kajiwara, I., Umenai, K.: Dynamic characterizations of underwater structures using non-contact vibration test based on nanosecond laser ablation in water: investigation of cavitation bubbles by visualizing shockwaves using the Schlieren method. J. Vib. Control 22, 3649-3658 (2016). https://doi.org/10.1177/10775463 14564693

33. Hosoya, N., Umino, R., Kajiwara, I., Maeda, S., Onuma, T., Mihara, A.: Damage detection in transparent materials using non-contact laser excitation by nano-second laser ablation and high-speed polarization-imaging camera. Exp. Mech. 56, 339-343 (2016). https://doi.org/10.1007/s11340-012-9646-9

34. Hosoya, N., Terashima, Y., Umenai, K., Maeda, S.: High spatial and temporal resolution measurement of mechanical properties in hydrogels by non-contact laser excitation. AIP Adv. 6, 095223-1-095223-8 (2016). https://doi.org/10.1063/1.4964305

35. Hosoya, N., Umino, R., Kanda, A., Kajiwara, I., Yoshinaga, A.: Lamb wave generation using nanosecond laser ablation to detect damage. J. Vib. Control (2017). https://doi.org/10.1177/10775463 16687904

36. Hosoya, N., Kajiwara, I., Umenai, K., Maeda, S.: Dynamic characterizations of underwater structures using noncontact vibration tests based on nanosecond laser ablation in water: evaluation of passive vibration suppression with damping materials. J. Vib. Control (2017). https://doi.org/10.1177/1077546317710158

37. Oksanen, M., Hietanen, J.: Photoacoustic breakdown sound source in air. Ultrasonics 32, 327-331 (1994). https://doi.org/10.1016/00 41-624X(94)90102-3
38. Qin, Q., Attenborough, K.: Characteristics and application of lasergenerated acoustic shock waves in air. Appl. Acoust. 65, 325-340 (2004). https://doi.org/10.1016/j.apacoust.2003.11.003

39. Georgiev, V.B., Krylov, V.V., Qin, Q., Attenborough, K.: Generation of flexural waves in plates by laser-initiated airborne shock waves. J. Sound Vib. 330, 217-228 (2011). https://doi.org/10.101 6/j.jsv.2010.08.005

40. Hosoya, N., Nagata, M., Kajiwara, I.: Acoustic testing in a very small space based on a point sound source generated by laserinduced breakdown: stabilization of plasma formation. J. Sound Vib. 332, 4572-4583 (2013). https://doi.org/10.1016/j.jsv.2013.0 3.035

41. Bolaños, J.G., Delikaris-Manias, S., Pulkki, V., Eskelinen, J., Hæggström, E.: Laser-induced acoustic point source for accurate impulse response measurements within the audible band width. J. Acoust. Soc. Am. 135, E-298-E-303 (2014). https://doi.org/10.11 21/1.4879664

42. Huda, F., Kajiwara, I., Hosoya, N.: Damage detection in membrane structures using non-contact laser excitation and wavelet transformation. J. Sound Vib. 333, 3609-3624 (2014). https://doi.org/10.1 016/j.jsv.2014.04.008

43. Zhang, Y., Hiruta, T., Kajiwara, I., Hosoya, N.: Active vibration suppression of membrane structures and evaluation with a non-contact laser excitation vibration test. J. Vib. Control 23, 1681-1692 (2015). https://doi.org/10.1177/1077546315599302

44. Hosoya, N., Nagata, M., Kajiwara, I., Umino, R.: Nano-second laser-induced plasma shock wave in air for non-contact vibration tests. Exp. Mech. 56, 1305-1311 (2016). https://doi.org/10.1007/s 11340-016-0167-9

45. Hosoya, N., Mishima, M., Kajiwara, I., Maeda, S.: Non-destructive firmness assessment of apples using a non-contact laser excitation system based on a laser-induced plasma shock wave. Postharvest Biol. Technol. 128, 11-17 (2017). https://doi.org/10.1016/j.postha rvbio.2017.01.014

46. Hosoya, N., Yoshinaga, A., Kanda, A., Kajiwara, I.: Non-contact and non-destructive Lamb wave generation using laser-induced plasma shock wave. Int. J. Mech. Sci. 140, 486-492 (2018). https:// doi.org/10.1016/j.ijmecsci.2018.03.023

47. Kajiwara, I., Akita, R., Hosoya, N.: Damage detection in pipes based on acoustic excitations using laser-induced plasma. Mech. Syst. Signal Process. 111, 570-579 (2018). https://doi.org/10.101 6/j.ymssp.2018.04.004 